Key words: Dual diagnosis, emergency room, psychiatric emergency services, severity of illness, psychiatric comorbidity, evaluation of services.

\title{
Dual diagnosis in the psychiatric emergency room in Spain
}

\author{
Rocío Martín-Santos, MD, PhD ${ }^{*, * *}$ \\ Francina Fonseca, MD* \\ Antonia Domingo-Salvany, $\mathrm{MD}^{\star * *}, \mathrm{PhD}$ \\ José María Ginés, MD* \\ María Luisa Ímaz, MD* \\ Ricard Navinés, MD*, PhD \\ Juan Carlos Pascual, MD* \\ Marta Torrens, MD, $\mathrm{PhD}^{\star}$ \\ * Drug Abuse and Psychiatric Department \\ (IAPS) Hospital del Mar, Barcelona \\ ** Pharmacologic Research Unit, Institut \\ Municipal d'Investigació Mèdica (IMIM), \\ Barcelona \\ *** Health Services Research Unit, Institut \\ Municipal d'Investigació Mèdica (IMIM), \\ Barcelona. Spain
}

SPAIN

\begin{abstract}
Background and Objectives: Dual diagnosis is associated with increased emergency department service use. During recent years, increased emphasis has been given to monitor the decision to hospitalise the most sever patients. Many rating scales have developed based on patient-related factors. To assess the level of severity of dual diagnosis patients measured by the Severity Psychiatric Illness (SPI) Scale and to evaluate it as a tool for predicting discharge in emergency psychiatric practice.

Methods: Data on 1,227 consecutive admissions visited in a psychiatric emergency room of a general teaching hospital during a period of six months were collected. A routine computerised protocol was completed which included socio-demographic, clinical and social factors and the SPI scale.

Results: 206 admissions (17\%) had dual diagnosis disorder, 106 (9\%) had substance abuse disorder (SUD), and 906 (74\%) had non-substance abuse disorder (NSUD). Differences among groups were found in clinical characteristics, discharge decision, readmissions, previous psychiatric history, reason for referral, DSM-IV diagnosis and illicit drug use. Dual diagnosed patients had the highest scores of severity. Logistic regression analyses revealed the independent contribution of different SPI'items. The model showed a good fit and indicated excellent calibration in the sample studied, predicting $87.6 \%$ of discharge decisions.
\end{abstract}


Conclusions: Dual diagnosed patients at the emergency psychiatric room presented the highest levels of severity both in clinical and social problems. While the SPI was a good tool for assessing severity of illness in our patients, only some dimensions predicted discharge decision.

\section{Introduction}

Evidence from both community and clinical samples have shown that the coexistence of substance abuse disorder (SUD) and non-substance abuse disorder (NSUD) is common ${ }^{1}$. Two recent longitudinal studies showed that this comorbid group is associated with substantially increased emergency department (ED) service $u^{2} e^{2}$ and significantly higher rates of psychiatric hospitalisation $^{3}$.

Specialised emergency psychiatric services play a critical role in the comprehensive care of patients with severe mental disorders. Although, the general tendency is to take care of patients in the community, hospitalisation still remains the proper setting for some acute periods of the illness. The psychiatric evaluation that is conducted in a psychiatric emergency service and the resulting case disposition, admission or discharge, has major effects on patients, community and health services. Over recent years, increased emphasis has been given to monitor the decision to hospitalise the most severe patients ${ }^{4,5}$, 6,7. Among the different aspects of the decision one is the severity of illness which is difficult to define and assess, and for which different approaches have been used ${ }^{4,6,7}$. Some authors have tried to develop rating scales based on patient-related factors to help with the complexity of the decision ${ }^{4,6,7}$. Suicide potential, danger to others, symptoms severity, and impaired capacity for self-care were found in different studies to be the best predictors of hospitalization. Other aspects focused on contextual factors such as differences between centres ${ }^{8,9}$, time of the day the patient arrived to the $\mathrm{ED}^{10}$, week of the month ${ }^{11}$ level of training of psychiatrist ${ }^{6,12}$, source of referral ${ }^{13}$, bed availability ${ }^{5}$ and system of care ${ }^{14}$.

The Severity of Psychiatric Illness (SPI) scale was developed as a patient-level decision support tool to assess need for services, specially inpatient care ${ }^{15,4}$. It is a rating scale based on patient's clinical and social factors. The SPI's validity has been established in a number of studies in different types of patients and settings, in psychiatric $\mathrm{ED}^{4,8}$, in mobile psychiatric emergency services ${ }^{16}$, acute units ${ }^{17}$ and geriatric units ${ }^{12}$. However, the importance of the SPI on the likelihood of admission of specific subgroups of patients such as dual diagnosis is less clear $^{7,17,18}$.

In this context, we hypothesised that dual diagnosis patients would differ from substance abuse and non-substance abuse groups in the level of severity and the need of hospitalisation. We therefore conducted a study to address the following research questions. First, are dual diagnosis patients a more severe subgroup in the emergency ward? And second, is the SPI scale a useful and practical tool for predicting discharge in emergency psychiatric practice? 


\section{Subjects and methods}

We studied prospectively all consecutive admissions into the 24-h psychiatric emergency ward within the ED of a general teaching hospital in Barcelona, during a period of six-months (December 2001-May 2002). The hospital attends an area of 330,000 inhabitants that includes a lowincome district.

An emergency psychiatric admission was defined as an emergency hospital admission to the psychiatric ward in persons over 18 years of age. Some persons had more than one emergency psychiatric admission during the study period.

The psychiatric emergency team includes one staff psychiatrist (who completed a clinical routine computerised protocol for every admission) and two nurses, covering a 24 hours schedule, and a part time social worker. Before the psychiatric visit any suspicion of a general medical condition causing the psychopathological symptoms is evaluated by the medical service.

The routine computerised protocol included different topics. Socio-demographic data: age, gender, ethnicity, immigrants, homeless, social problems and district of origin. Reason for referral was coded by broad complaints categories such as: psychotic, disruptive behaviour, anxious, depressed, and related to drug use (intoxication, withdrawal, requesting treatment). Referral source is the person or agency who initiated the referral to the ED and includes: self-referrals, ambulance (sent by the "061", the out-of-hospital urban public emergency services), police referrals or internal referrals (inpatients in medical observation). Others variables included: information about previous contact to a treatment centre; pattern of drug abuse (main drug use) and current route of drug use (oral, smoking, snorting and intravenous); presence of HIV infection as well as psychiatric history (any previous contact with mental health or substance use services or readmission in ED); and the degree of severity of illness using the Spanish version of the SPI ${ }^{19}$. Finally, patient discharge was coded as: hospitalisation, outpatient's mental health or substance abuse community centre, and others (mainly general practitioner). A urine screening test was carried out only when the clinician needed the information to clarify the diagnosis.

Every psychiatric ED admission received a mental disorder diagnosis according to the DSM-IV criteria. For the analysis we collapsed the major mental disorders into five categories: schizophrenia spectrum disorders, affective disorders, anxiety disorders, others axis I, and personality disorders.

The SPI is a hetero-administered rating scale of 12 dimensions with four possible responses. The possible scores range from 0 (denoting absence of severity in that item) to 3 (maximal severity). Specific domains include suicide risk, danger to others, severity of symptoms, difficulty with self-care, medical complications, drugs problems, job problems, family disruption, home instability, treatment denial, family involvement, and premorbid dysfunction ${ }^{4,17}$. The SPI was completed at the end of the emergency care utilizing all possible sources of information (patient, family, clinical records, social worker). Completing the instrument took five to ten minutes.

For the purpose of the present study we divided the sample in three groups: dual diagnosis, NSUD and SUD. Because the study used the regular admissions database we did not ask for informed consent however, the main principles outlined in the 
Declaration of Helsinki were followed. All data were entered into SPSS. $12 \mathrm{v}$. To determine whether clinical and socio-demographic variables and SPI scores were significantly different in dual diagnosis, SUD and NSUD admissions, univariate analysis was carried out using the chi-square, ANOVA and non-parametric tests. Then, we compared the percentage of moderate (score $=2$ ) and severe (score $=3$ ) rating of each SPI dimension between patients hospitalised from those released. All $\mathrm{p}$ values reported are two-tailed and statistical significance was set at 0.05 . Multivariate logistic regression modelling techniques were applied to the combined data to assess the relative contribution of variables to the discharge decision; goodness-of-fit was assessed through the HosmerLemeshow statistic ${ }^{20}$.

\section{Results}

During the six-month period of the study there were a total of 1,227 admissions to the psychiatric emergency ward. These psychiatric emergencies accounted for 3\% of all emergency admissions at ED, and involved 1,012 distinct patients. From these 1,227 psychiatric admissions, 912 (76\%) presented a NSUD, 106 (9\%) were only a SUD and $209(17 \%)$ admissions were in relation to dual diagnosis.

The background characteristics of the three groups are shown in Table I. Males were more frequent in the dual diagnosis and SUD groups. The mean age of the NSUD group was significantly higher. In the three groups around $90 \%$ of admissions were Caucasians and there were no differences in the percentage of immigrants between them.

Table I

Comparison of background characteristics between groups.

\begin{tabular}{|c|c|c|c|c|c|c|c|c|c|}
\hline \multirow{2}{*}{$\begin{array}{l}\text { Variables } \\
\text { Men; n (\%) }\end{array}$} & \multicolumn{2}{|c|}{$\begin{array}{l}\text { Dual diagnosis } \\
\quad \mathrm{N}=209\end{array}$} & \multicolumn{2}{|c|}{$\begin{array}{l}\text { NSUD* } \\
\mathrm{N}=912\end{array}$} & \multicolumn{2}{|c|}{$\begin{array}{c}\text { SUD* } \\
\mathrm{N}=106\end{array}$} & \multirow{2}{*}{$\frac{\chi^{2} ; \mathrm{F}}{119.531}$} & \multirow{2}{*}{$\frac{\mathrm{df}}{2}$} & \multirow{2}{*}{$\frac{\mathrm{p}}{<.001}$} \\
\hline & 155 & $(74.2)$ & 352 & (38.6) & 79 & $(74.5)$ & & & \\
\hline Age; mean [SD] & 37.19 & [10.79] & 41.6 & [17.0] & 37.76 & $5[10.17]$ & 8.550 & 2.1222 & $<.001$ \\
\hline Immigrants; n (\%) & 23 & (11.0) & 119 & (13.0) & 185 & $(14.2)$ & .827 & 2 & .661 \\
\hline Homeless; n (\%) & 24 & (11.5) & 43 & $(4.7)$ & 7 & $(6.6)$ & 13.812 & 2 & .001 \\
\hline Social problems; $\mathrm{n}(\%)$ & 146 & $(69.9)$ & 273 & (29.9) & 65 & $(61.3)$ & 136.697 & 2 & $<.001$ \\
\hline \multicolumn{10}{|l|}{ District origin; $\mathrm{n}(\%)$} \\
\hline Ciutat Vella & 75 & (35.9) & 287 & (31.5) & 40 & $(38.1)$ & 18.517 & 4 & .001 \\
\hline Sant Martí Sud & 54 & $(25.8)$ & 283 & (31.1) & 13 & (12.4) & & & \\
\hline Others & 100 & $(38.3)$ & 341 & (37.4) & 52 & $(49.6)$ & & & \\
\hline Previous MHS** contact; $\mathrm{n}(\%)$ & ) 173 & $(85.8)$ & 590 & $(64.7)$ & 81 & $(76.4)$ & 29.038 & 2 & $<.001$ \\
\hline \multicolumn{10}{|l|}{ Referral source; n (\%) } \\
\hline Self & 110 & $(52.6)$ & 580 & (63.6) & 58 & $(54.7)$ & 19.735 & 6 & .003 \\
\hline Ambulance & 81 & $(38.8)$ & 287 & (31.5) & 35 & $(33.0)$ & & & \\
\hline Police & 10 & $(4.8)$ & 17 & (1.9) & 5 & $(4.7)$ & & & \\
\hline Internal referrals & 8 & (3.8) & 28 & (3.1) & 8 & (7.5) & & & \\
\hline Readmission in 30 days; $\mathrm{n}(\%)$ & 58 & $(27.8)$ & 107 & (11.7) & 5 & (4.7) & 44.673 & 2 & $<.001$ \\
\hline
\end{tabular}

*SUD: Substance Use Disorders; NSUD: Non Substance Use Disorders

**MHS: Mental Health Services (psychiatric or substance abuse). 
Comparing the clinical characteristics and discharge decision between the dual diagnosis, SUD and NSUD groups some differences were found (Table II). Fifty-six percent of dual diagnosis admissions were diagnosed of an axis I DSM-IV disorder and $44 \%$ were diagnosed of an axis II
DSM-IV disorder. Among dual diagnosis admissions there were $24(14 \%)$ substanceinduced disorders in axis I (affective, anxiety and schizophrenia). On the other hand, the dual diagnosis group had higher prevalence of cannabis, cocaine and other illicit drug use.

Table II

Comparison of clinical characteristics and discharge decision between dual diagnosis, NSUD, and SUD groups.

\begin{tabular}{|c|c|c|c|c|c|c|c|c|}
\hline \multirow{2}{*}{$\begin{array}{l}\text { Variables } \\
\text { Previous psychiatric history; n (\%) }\end{array}$} & \multicolumn{2}{|c|}{$\begin{array}{c}\text { Dual diagnosis } \\
\qquad \mathrm{N}=209\end{array}$} & \multicolumn{2}{|c|}{$\begin{array}{l}\text { NSUD* } \\
\mathrm{N}=912\end{array}$} & $\begin{array}{c}\text { SUD* } \\
\mathrm{N}=106\end{array}$ & \multirow{2}{*}{$\frac{\chi^{2} ; \mathrm{F}}{32.445}$} & \multirow{2}{*}{$\frac{\mathrm{df}}{2}$} & \multirow{2}{*}{$\frac{\mathrm{p}}{<.001}$} \\
\hline & 183 & $(87.6)$ & 650 & $(71.3)$ & $92(86.8)$ & & & \\
\hline \multicolumn{9}{|l|}{ Reason for referral; n (\%) } \\
\hline Depression & 47 & $(22.5)$ & 267 & $(29.3)$ & $6 \quad(1.9)$ & \multirow[t]{6}{*}{661.581} & \multirow[t]{6}{*}{10} & \multirow[t]{6}{*}{$<.001$} \\
\hline Anxiety & 16 & $(7.7)$ & 336 & $(36.8)$ & $0 \quad(0)$ & & & \\
\hline Psychosis & 23 & $(11.0)$ & 111 & $(12.2)$ & $0 \quad(0)$ & & & \\
\hline Disruption behaviour & 34 & $(16.3)$ & 91 & $(10.0)$ & $11(10.4)$ & & & \\
\hline Drug use related & 67 & $(32.1)$ & 0 & $(0)$ & $80(75.5)$ & & & \\
\hline Others & 22 & $(10.5)$ & 107 & $(11.7)$ & $9 \quad(8.5)$ & & & \\
\hline \multicolumn{9}{|c|}{ Drug use related reasons for referral; n $(\%)$} \\
\hline Withdrawal syndrome & 6 & $(9.0)$ & & & $18(22.5)$ & \multirow[t]{3}{*}{4.972} & \multirow[t]{3}{*}{2} & \multirow[t]{3}{*}{.083} \\
\hline Drug intoxication & 29 & $(43.3)$ & & & $31(38.8)$ & & & \\
\hline Requesting treatment & 32 & $(47.8)$ & & & $31(38.8)$ & & & \\
\hline \multicolumn{9}{|l|}{ Main drug of abuse; n (\%) } \\
\hline Alcohol & 91 & $(43.5)$ & & & $56(52.8)$ & \multirow[t]{6}{*}{20.116} & \multirow[t]{6}{*}{5} & \multirow[t]{6}{*}{.001} \\
\hline Heroin/others opioid & 39 & $(18.7)$ & & & $33(31.2)$ & & & \\
\hline Cocaine & 29 & $(13.9)$ & & & $11(10.4)$ & & & \\
\hline Cannabis & 23 & $(11.0)$ & & & $2(1.9)$ & & & \\
\hline Benzodiazepine & 21 & $(10.0)$ & & & $3 \quad(2.8)$ & & & \\
\hline Others illicit drugs & 6 & $(2.9)$ & & & $1 \quad(0.9)$ & & & \\
\hline \multicolumn{9}{|l|}{ Main route used; n (\%) } \\
\hline Oral & 140 & $(67.3)$ & & & $74(72.5)$ & \multirow[t]{4}{*}{3.879} & \multirow[t]{4}{*}{3} & \multirow[t]{4}{*}{.275} \\
\hline Smoking & 27 & $(13.0)$ & & & $6 \quad(5.9)$ & & & \\
\hline Snorting & 25 & $(12.0)$ & & & $12(11.8)$ & & & \\
\hline IV** & 16 & $(7.7)$ & & & $10 \quad(9.8)$ & & & \\
\hline \multicolumn{9}{|c|}{ Non-substance DSM-IV diagnoses***; n (\%) } \\
\hline Affective disorders & 43 & $(20.6)$ & 312 & $(34.2)$ & & \multirow[t]{5}{*}{99.159} & \multirow[t]{5}{*}{4} & \multirow[t]{5}{*}{$<.001$} \\
\hline Anxiety disorders & 26 & (12.4) & 199 & $(21.8)$ & & & & \\
\hline Schizophrenia spectrum & 32 & $(15.3)$ & 165 & (18.1) & & & & \\
\hline Others axis I disorders & 17 & $(8.1)$ & 111 & $(12.2)$ & & & & \\
\hline Personality disorder & 91 & $(43.5)$ & 125 & $(13.7)$ & & & & \\
\hline Number of visits; mean [SD] & & $6[1.52]$ & & $3[1.42]$ & $1.12[.55]$ & 3.017 & 15.1211 & $<.001$ \\
\hline Discharge decision; $\mathrm{n}(\%)$ & & & & & & & & \\
\hline Hospitalization & 33 & $(15.8)$ & 136 & $(14.9)$ & $2 \quad(1.9)$ & 71.803 & 4 & $<.001$ \\
\hline $\begin{array}{l}\text { Outpatients mental health/ } \\
\text { substance abuse }\end{array}$ & 158 & $(75.6)$ & 527 & $(57.8)$ & $96(90.6)$ & & & \\
\hline Others & 18 & $(8.6)$ & 249 & $(27.3)$ & $8 \quad(7.5)$ & & & \\
\hline
\end{tabular}

*SUD: Substance Use Disorders; NSUD: Non Substance Use Disorders.

**IV: Intravenous.

***Among dual diagnosis admission there were 24 induced disorders. 
The SPI scores for the three admission groups are shown in Table III. Dual diagnosed subjects had the highest total score of severity. Univariate analysis of the association between SPI items severity and dispo- sition showed that psychiatric emergency admissions which end in hospitalisation had higher severity on all the items except medical complications and drug problems (Table IV).

Table III

Comparison of the Severity of Psychiatric Illness (SPI) scale scores between the three groups.

\begin{tabular}{lccrrr} 
Items & $\begin{array}{c}\text { Dual diagnosis }(\mathrm{n}=209) \\
\text { Mean }(\text { median) }\end{array}$ & $\begin{array}{c}\text { NSUD* }(\mathrm{n}=912) \\
\text { Mean }(\text { median) }\end{array}$ & $\begin{array}{r}\text { Mean (median) } \\
\text { SUD* }(\mathrm{n}=106)\end{array}$ & \multicolumn{1}{c}{$\mathrm{p}^{* *}$} \\
\hline Suicide risk & $.72(1.00)$ & $.57(.00)$ & .41 & $(.00)$ & .001 \\
Danger to others & $.79(1.00)$ & $.32(.00)$ & .58 & $(.00)$ & $<.001$ \\
Severity of symptoms & $1.89(2.00)$ & $1.84(2.00)$ & $1.51(2.00)$ & $<.001$ \\
Self-care ability & $.91(1.00)$ & $.75(1.00)$ & $.67(1.00)$ & $<.001$ \\
Medical complications & $1.03(1.00)$ & $.58(.00)$ & $1.09(1.00)$ & $<.001$ \\
Drugs problems & $2.28(3.00)$ & $.21(.00)$ & $2.60(3.00)$ & $<.001$ \\
Job problems & $1.15(1.00)$ & $.61(.00)$ & $1.17(1.00)$ & $<.001$ \\
Family disruption & $1.81(2.00)$ & $1.23(1.00)$ & $1.52(2.00)$ & $<.001$ \\
Home instability & $.74(0.00)$ & $.34(.00)$ & .45 & $(.00)$ & $<.001$ \\
Denied of treatment & $.47(0.00)$ & $.41(.00)$ & .40 & $(.00)$ & .069 \\
Family involvement & $1.35(1.00)$ & $.81(.00)$ & $1.16(1.00)$ & $<.001$ \\
Pre-morbid dysfunction & $1.37(1.00)$ & $.95(1.00)$ & $1.23(1.00)$ & $<.001$ \\
Total score & $14.48(14.00)$ & $8.63(8.00)$ & $12.58(12.00)$ & $<.001$ \\
\hline
\end{tabular}

*SUD: Substance Use Disorders; NSUD: Non Substance Use Disorders.

**Non-parametric Kruskal-Wallis Test.

Logistic regression analyses revealed the independent contribution of different items of the SPI (severity of symptoms, suicide risk and self-care ability, denied of treatment and homeless) as well as the diagnostic group and age, in the decision to hospitalize the patient from the emergency psychiatric ward (Table V). The model, adjusted for gender, showed a good fit $\left(\chi^{2}=\right.$ 12.669; df $=8$; $\mathrm{p}>0.05)$ in the HosmerLemeshow statistic and indicated excellent calibration in the sample studied, predicting $87.6 \%$ of discharge decisions $(97 \%$ of those not admitted and $30.6 \%$ of those admitted).

\section{Discussion}

The results of the study confirmed our hypothesis that admissions at the psychi- atric emergency room had a different level of severity of illness depending on whether patients had been diagnosed of dual diagnosis, SUD or NSUD. And, in fact, dual diagnosis presented the highest level of severity, coming both from clinical and social dimensions. While the SPI was a good tool for assessing severity of illness in our patients, only some dimensions of it predicted discharge decision: severity of symptoms, suicide risk, self-care ability, denied of treatment and homeless.

To our knowledge this is the first study to assess the severity of illnesses using the SPI, in a non-English country, in the psychiatric emergency room. During the six-month period studied, one in every six admissions to the psychiatric emergency ward had a dual diagnosis disorder. This figure varied depending on the setting and health care system in wish the prevalence study is done $\mathrm{e}^{21,22}$. Patients 
Table IV

Univariated relationship between Severity of Psychiatry Illness scale (SPI) ratings and hospital admission.

\begin{tabular}{lcrrrr} 
Items & $\begin{array}{c}\text { Admitted }(\mathrm{n}=173) \\
\mathrm{N} *(\%)\end{array}$ & $\begin{array}{c}\text { Not admitted }(\mathrm{n}=1,054) \\
\mathrm{N}(\%)\end{array}$ & \multicolumn{1}{c}{$\chi^{2}$} & $\mathrm{df}$ & $\mathrm{p}$ \\
\hline Suicide risk & $47(27.5)$ & $94(8.9)$ & 48.660 & 1 & $<.001$ \\
Danger to others & $39(22.8)$ & $84(8.0)$ & 34.994 & 1 & $<.001$ \\
Severity of symptoms & $157(91.8)$ & $657(62.2)$ & 59.066 & 1 & $<.001$ \\
Self-care ability & $80(46.8)$ & $147(13.9)$ & 102.802 & 1 & $<.001$ \\
Medical complications & $41(24.0)$ & $237(22.4)$ & .302 & 1 & .583 \\
Drugs problems & $46(26.9)$ & $273(25.9)$ & .320 & 1 & .572 \\
Job problems & $52(30.4)$ & $232(22.0)$ & 7.332 & 1 & .007 \\
Family disruption & $93(54.4)$ & $489(46.3)$ & 4.520 & 1 & .034 \\
Home instability & $42(24.6)$ & $107(10.1)$ & 30.490 & 1 & $<.001$ \\
Denied of treatment & $65(38.0)$ & $66(6.3)$ & 152.766 & 1 & $<.001$ \\
Family involvement & $66(38.6)$ & $279(26.4)$ & 11.219 & 1 & .001 \\
Premorbid dysfunction & $82(48.0)$ & $314(29.7)$ & 22.637 & 1 & $<.001$ \\
\hline
\end{tabular}

$* \mathrm{~N}$ and percentage of each item with moderate and severe score in the SPI.

Table V

Logistic Regression assessing the relative contributions of different items of the Severity of Psychiatric Illness scale to patient hospitalisation, taking into account diagnostic groups, for 1,227 psychiatric emergency admissions.

\begin{tabular}{lccc} 
& Beta & Odds ratio $(95 \% \mathrm{CI})$ & $\mathrm{p}$ \\
\hline Group: & & .005 & \\
$\quad$ Dual diagnosis & 0.264 & $1.3(0.78-2.17)$ & .312 \\
NSUD* & -1.836 & $0.16(0.04-0.61)$ & .008 \\
SUD* & & & .023 \\
Age: & & & .013 \\
$\quad>45$ years & 0.638 & $1.89(1.15-3.12)$ & .018 \\
31-45 years & 0.577 & $1.78(1.10-2.87)$ & \\
18-30 years & & & .191 \\
Gender: & & & $<.001$ \\
$\quad$ Male & -0.262 & $0.77(0.52-1.14)$ & $<.001$ \\
$\quad$ Female & 1.259 & $3.52(2.23-5.57)$ & .001 \\
Suicide risk & 1.211 & $3.36(1.85-6.08)$ & .003 \\
Severity of symptoms & 1.191 & $3.29(2.18-4.97)$ & $<.001$ \\
Self-care ability & 0.745 & $2.11(1.28-3.47)$ & \\
Home instability & 1.849 & $6.35(4.01-10.07)$ & \\
Denied of treatment & & &
\end{tabular}

* SUD: Substance Use Disorders; NSUD: Non Substance Use Disorders.

with dual diagnosis were those with the highest severity and shared the clinical severity of symptoms with NSUD patients, but drug problems, pre-morbid dysfunction and medical complications with SUD. The presence of severe psychopathology such as psychosis or an affective or personality disorder could explain the high score in the severity of symptoms dimension as well as in the danger to others. To compare the present prevalence 
of an axis II or I disorder in this group is difficult because there are no previous similar studies, and other samples in the literature used different criteria ${ }^{3}$. In our sample suicide risk was also high, as previous studies have found in persons with dual diagnosis, especially for individuals with bipolar disor$\operatorname{ders}^{23,24}$. Dual diagnosis patients showed poorer self-care ability than the other two groups, reflecting the high level of clinical severity of such patients. Despite the fact that both dual diagnosis and NSUD had the same percentage of hospitalisation, dual diagnosis had a significantly higher rate of readmission in 30 days. Different reasons have been argued for this "revolving door" effect and are related with the severity itself but also with differences in the type of services offered by the health system ${ }^{3,25}$. This was done in a context of a National Heath Care Services who provides universal access. We work with two community mental health networks, similarly to other European countries, one of them targeting severe chronic mental illness and the other substance abuse disorders. Both networks, working in parallel, make the suitable allocation of dual diagnosis patients difficult. On the other hand, dual diagnosis patients shared severe social factors with SUD. Home instability, family disruption and lack of family involvement in the treatment, higher in dual diagnosis than SUD, increased global severity of illness in both groups together with job problems. The dual diagnosis and SUD groups had the same level of medical complications; some of them related to the concomitant HIV infection. Denied of treatment didn't allow to differentiate severity between the three groups.

The logistic regression model identified several SPI clinical dimensions and home instability to predict hospitalisation. Results were consistent with previous studies on severity of symptoms, suicide risk and self- care ability ${ }^{4,7}$. In contrast with earlier studies denied of treatment and home instability were factors, which independently predicted the admission in our study $4,7,8$. Denied of treatment could express lack of willingness to acknowledge need for help of patients but it is also a variable that might be influenced by the laws concerning compulsory hospitalisation and the mental health system of each country ${ }^{14}$. Homelessness is an increasingly serious problem among patients with severe mental illness. Recently, a large epidemiological study has shown that it is associated with male gender, presence of substance disorders, a diagnosis of schizophrenia or bipolar disorders and poor functioning. In this study, homeless patients used more inpatient and emergency services $^{26}$. Other variables that entered into the model were diagnostic group and age. In spite of the high level of severity of their illness, SUD patients were almost all discharged. That occurred because under our health system, to be admitted in the detoxification unit the decision should be taken by the substance abuse community team. Patients under 45 years were admitted nearly twice as frequently as those over 45 . Earlier studies have reported conflicting results for substance abuse $e^{5,7}$ and demographic variables $^{6,26}$. Other dimensions from the SPI did not enter into the model. Although danger to others has been associated with hospitalisation in most of the studies $4,17,18$ our results are similar to those in which it was not found to be associated ${ }^{8,27}$. Finally, although the model correctly predicted the $87 \%$ of discharge decisions it only explained $31 \%$ of hospitalization suggesting that other variables not studied may play a role. To adequately interpret those proportions in relation to other studies it is important to take into account that our rate of hospitalisation was comparatively low (14\%). 
In order to generalise our results a clear limitation is that the results presented were based on data collected in only one psychiatric emergency ward of an urban general teaching hospital. However, the sample was well defined to provide other researchers the complete information to compare to in future studies. Another potential limitation is the accuracy of the dual diagnosis itself ${ }^{28}$ and indeed of any diagnosis made in the psychiatric emergency setting ${ }^{2,29}$. In spite of this, all psychiatrists were senior staff with considerable experience in drug abuse and dual diagnosis and, although toxicological confirmation of substance use was only obtained in some cases, a previous study does not support routine use of drug screens in psychiatry emergency services since they do not modify clinical and discharge decisions ${ }^{30}$.

In conclusion, results of the study support the need to adequately assess the degree of severity of psychiatric patients in the emergency room. The SPI scale was a good tool for measuring severity of illness in this setting, although future studies should be done to establish is capability to predict hospitalization of dual diagnosed patients. Dual diagnosed patients at the emergency psychiatric room presented the highest levels of severity both in clinical and social problems. These were reflected in high rates of previous contact with health services, higher hospitalisation than NSUD and in the higher frequency of readmission at the emergency department. Adequate care for these patients should consider, both the comprehensive psychiatric care and social aspects related to drug abuse. Our results support recent recommendation of experts ${ }^{31}$ proposing that integrated treatment of persons with co-occurring mental and substance use disorders must be recognised as the standard of care, particularly for nonresponding or severely ill patients.

\section{Acknowledgment}

This study was supported in part by the Ajuts de Support als Grups de Recerca de Catalunya (2001/SGR:00412), Red de Trastornos Adictivos (FIS:GO3/005) and Red de Genotipación y Psiquiatría Genética (FIS:G03/184).

\section{References}

1. Hasin D, Nunes E. Comorbidity of alcohol, drug, and psychiatric disorders: epidemiology. In: Kranzler HR, Tinsley JA eds. Dual diagnosis and psychiatric treatment: Substance Abuse and Comorbid Disorders. $2^{\text {nd }}$ edn. New York: Marcel Dekker Inc.; 2004. p. 1-33.

2. Lejoyeux M, Boulenguiez S, Fichelle A, McLoughlin M, Claudon M, Ades J. Alcohol dependence among patients admitted to psychiatric emergency services. Gen Hosp Psychiatry 2000; 22: 206-212.

3. Curran GM, Sullivan G, Williams K, Han X, Collins $\mathrm{K}$, Keys J, et al. Emergency department use of persons with comorbid psychiatric and substance abuse disorders. Ann Emerg Med 2003; 41: 659-667.

4. Lyons JS, Stutesman J, Neme J, Vessey JT, O’Mahoney MT, Camper HJ. Predicting psychiatric emergency admissions and hospital outcome. Med Care 1997a; 35: 791-800.

5. Moos RH, Nichol AC, Moos BS. Global assessment of functioning rating and the allocation and outcomes of mental health services. Psychiatr Serv 2002; 53: 730-737.

6. Slangg NB. Characteristics of emergency room patients that predict hospitalization or disposition to alternative treatments. Hosp Community Psychiatry 1993; 44: 252256.

7. Way BB, Banks S. Clinical factors related to admission and release decisions in psychiatric emergency services. Psychiatr Serv 2001; 52: 214-218.

8. George L, Durbin J, Sheldon T, Goering P. Patient and contextual factors related to the decision to hospitalize 
patients from emergency psychiatric services. Psychiatr Serv 2002; 53: 1586-1591.

9. Rabinowitz J, Mark M, Slyuzberg M. How individual clinicians make admission decisions in psychiatric emergency rooms. J Psychiatr Res 1994; 28: 475-482.

10. Marson DC, McGovern MP, Pomp HC. Psychiatric decision making in the emergency room: a research overview. Am J Psychiatry 1998; 145: 918-925.

11. Maynard C, Cox GB. Association between week of the month and hospitalisation for substance abuse. Psychiatr Serv 2000; 51: 31.

12. Fichtner C, Flaberty J. Emergency psychiatry training and the decision to hospitalize. Acad Psychiatry 1993; 17: 585-586.

13. Dhossche DM, Ghani SO. Who brings patients to the psychiatric emergency room? Gen Hosp Psychiatry 1998; 20: 235-240.

14. Catalano R, McConnell W, Forster P, McFarland B, Thornton D. Psychiatric emergency services and the system of care. Psychiatr Serv 2003; 54: 351-355.

15. Lyons J, Colletta J, Devens M. Validity of Severity of Psychiatric Illness rating scale in a sample of inpatients on a psychogeriatric unit. Int Psychogeriatr 1995; 7: 407416.

16. Mulder CL, Koopmans GT, Lyons JS. Determinants of indicated versus actual level of care in psychiatric emergency services. Psychiatr Serv 2005; 56: 452-457.

17. Lyons JS, O’Mahoney MT, Miller SI, Neme J, Kabat J, Miller F. Predicting readmission to the Psychiatric Hospital in a managed care environment: Implications for quality indicators. Am J Psychiatry 1997b; 154: 337-340.

18. Rabinowitz J, Massad A, Fenning S. Factors influencing disposition decisions for patients seen in a psychiatric emergency services. Psychiatr Serv 1995; 46: 712718.

19. Bulbena A, Pompei S, Ollé L, Coletas J. Medida de la gravedad de la enfermedad psiquiátrica. Arch Neurobiol 1997; 7(Supl. 2): s69-s79.

20. Hosmer DW, Lemershow S. Applied logistic regression. New York: Wiley; 1989.

21. Elangovan N, Berman S, Meinzer A. Substance abuse among patients presenting at an inner city psychiatric emergency room. Hosp Community Psychiatry 1993; 44: 782-784.

22. Lambert MT. Psychiatric intervention in the general emergency service of a Veterans Affairs hospital. Psychiatr Ser 1995; 46: 283-284.
23. Dalton EJ, Cate-Carter TD, Mundo E, Parikh SV, Kennedy JL. Suicide risk in bipolar patients: the role of comorbid substance use disorders. Bipolar Disor 2003; 5: 58-61.

24. Kelly TM, Cornelius JR, Lynch KG. Psychiatric and substance use disorders as risk factors for attempted suicide among adolescents: a case control study. Suicide Life Threat Behav 2002; 32: 301-312.

25. Lambert MT, LePage JM, Schmitt AL. Five-year outcomes following psychiatric consultation to a tertiary care emergency room. Am J Psychiatry 2003; 160: 13501353.

26. Folsom DP, Hawthotne W, Lindamer L, Gilmer T, Bailey A, Golshan S, et al. Prevalence and risk factors for homelessness and utilization of mental health services among 10,340 patients with serious mental illness in a large public mental health system. Am J Psychiatry 2005; 162: $370-376$.

27. McNiel DE, Myers RS, Zeiner HK, Wolfe HL, Hatcher C. The role of violence in decisions about hospitalization from the psychiatric emergency room. Am J Psychiatry 1992; 149: 207-212.

28. Torrens M, Serrano D, Astals M, Perez-Dominguez G, Martin-Santos R. Diagnosing psychiatric comorbidity in substance abusers. Validity of the Spanish versions of Psychiatric Research Interview for Substance and Mental Disorders (PRISM-IV) and the Structured Clinical Interview for DSM-IV (SCID-IV). Am J Psychiatry 2004; 161:12311237.

29. Way B, Allen MH, Mumpower JL, Stewart TR, Banks SM. Interrater agreement among psychiatrists in psychiatric emergency assessments. Am J Psychiatry 1998; 155: $1423-1428$.

30. Schiller MJ, Shumway M, Batki SL. Utility of routine drug screening in a psychiatric emergency setting. Psychiatr Serv 2000; 51: 474-478.

31. O'Brien CP, Charney DS, Lewis L, Cornish JW, Post RM, Woody GE, et al. Priority actions to improve the care of persons with co-occurring substance abuse and other mental disorders: a call to action. Biol Psychiatry 2004; 56: 703-713.

Address for correspondence:

Dra. Rocío Martín-Santos

Pharmacologic Research Unit (IMIM)

Institut Municipal d'Investigació Mèdica- Hospital del Mar Dr Aiguader, 80, E-08003 Barcelona, Spain

Telephone number: +34 932483180, fax +34 932213237

e-mail: rmsantos@imim.es

SPAIN 